\title{
The consumption and disposition behaviour of voluntary simplifiers
}

\author{
Paul W. Ballantine ${ }^{1 *}$ and Sam Creery ${ }^{2}$ \\ ${ }^{1}$ Department of Management, University of Canterbury, New Zealand \\ ${ }^{2}$ Colgate-Palmolive Ltd, Auckland, New Zealand
}

- Voluntary simplicity is a lifestyle choice that has received increasing media attention over time. A defining characteristic of voluntary simplicity is a reduced material consumption and the removal of clutter from one's life, thus suggesting the topic of disposition may inform our understanding of voluntary simplifier lifestyle behaviour. This paper explores the disposition activities of voluntary simplifiers in the context of their overall consumption behaviour using a series of in-depth interviews with 12 current voluntary simplifiers. The findings show that disposition plays an important role in voluntary simplifier behaviour, especially during the initial stages of adopting the lifestyle. The consideration of future disposition activities was also found to influence the day-to-day consumption behaviour of participants.

Copyright (C) 2009 John Wiley \& Sons, Ltd.

Do we have too much stuff? Could we be just as happy, or happier, with less stuff? Is it possible to bave less stuff without feeling deprived?

- Karp (2009)

\section{Introduction}

Questions like the ones above have increasingly been asked in the popular press. As Karp (2009) notes, advocates of the voluntary simplicity movement say the answers are: yes, yes and yes. The increasing media

\footnotetext{
*Correspondence to: Paul W. Ballantine, Department of Management, University of Canterbury, Private Bag 4800, Christchurch 8140, New Zealand.

E-mail: paul.ballantine@canterbury.ac.nz
}

attention given to the practice of voluntary simplicity is also thought to be a reflection of the number of people now adopting the lifestyle (Maniates, 2002). However, the academic literature on voluntary simplicity is rather limited, with most papers focussing on either defining or operationalising the term (e.g. Etzioni, 1998; Iyer and Muncy, 2009; Leonard-Barton, 1981), exploring the motivations behind the lifestyle (e.g. Zavestoski, 2002), or examining the experiences of voluntary simplifiers (e.g. Bekin et al., 2005; CraigLees and Hill, 2002).

A defining characteristic of voluntary simplicity is reducing material consumption and removing the 'clutter' from one's life (Zavestoski, 2002), thus suggesting the literature on disposition (e.g. Jacoby et al., 1977; Lastovicka and Fernandez, 2005) may inform our understanding of voluntary simplifier lifestyle 
behaviour. The focus of this paper is to explorethe disposition activities of voluntary simplifiers in the context of their overall consumption behaviour. We explore these areas as consumption and disposition play a symbiotic role in the voluntary simplicity lifestyle. While voluntary simplicity necessitates a reduction in consumption (Shaw and Newholm, 2002), within the context of reducing consumption, disposition activities also occur. When adopting the lifestyle, voluntary simplifiers enter a concentrated period of de-cluttering where they must be able to dispose of goods, and decouple notions of identity from these goods (Nelson et al., 2007). Then, once fully immersed in the lifestyle, voluntary simplifiers exhibit changes in consumption due to their lessened focus on material wealth (Craig-Lees and Hill, 2002), where disposition inevitably plays an ongoing role.

\section{Literature review}

The idea of voluntary simplicity was first introduced by Gregg (1936), who took his inspiration from the great spiritual leaders of history who he believed practiced the lifestyle. Gregg (1936: p. 4) defines voluntary simplicity as having 'singleness of purpose, sincerity and honesty within, as well as avoidance of exterior clutter, of many possessions irrelevant to the chief purpose of life'. More recently, Etzioni (1998: p. 620) defines the practice as 'the choice out of free will ... to limit expenditures on consumer goods and services, and to cultivate non-materialistic sources of satisfaction and meaning'. This definition also emphasises the voluntary nature of the lifestyle through free will, not through coercion by authorities or as a means of budgeting through tough economic times (Leonard-Barton, 1981). More recently, Craig-Lees and Hill (2002) identify the following five themes of voluntary simplicity: freedom of choice to lead a simpler life; a reduction in material consumption; access to resources like wealth, education and unique skills which can be traded for a high income; control and personal fulfilment; and being driven by values such as humanism, self-determination, environmentalism, spirituality and self-development.

Etzioni (1998) argues that consumers can adopt the lifestyle on a sliding scale of involvement, identifying three levels of intensity: downshifters, strong simplifiers and holistic simplifiers. Downshifters are moderate simplifiers, forgoing some consumer goods while maintaining the majority of their consumer lifestyle. Bekin et al. (2005) liken this to conspicuous simplicity, where old possessions are replaced (possibly at great expense) with items that symbolise their new simplified lifestyle. Taylor-Gooby (1998) goes further, stating that downshifters may be in contradiction to the lifestyle as their affluence is retained, thus contradicting the ideology. Strong simplifiers are those who give up high-paying jobs in order to live on much less income, restricting their consumption accordingly. These simplifiers also include those who are motivated to reduce the time they spend at work. Holistic simplifiers are similar to strong simplifiers, but adjust their entire lifestyle to fit the voluntary simplicity ethic; this can involve moving house to a less-affluent area (perhaps rural) with the intention of leading a simpler life (Etzioni, 1998).

Maslow's Hierarchy of Needs informs much of the literature on voluntary simplicity (Etzioni, 1998; Huneke, 2005; Zavestoski, 2002). Etzioni (1998) proposes that once people have satisfied their lower-end needs, they may look to voluntary simplicity as a viable option for achieving their higher-end needs. Huneke (2005) echoes this, positing that voluntary simplifiers may realise they have needs that material consumption is incapable of satisfying. Zavestoski (2002) takes a slightly different approach, modifying the hierarchy by splitting the top tier (self-actualisation) into two: efficacy and authenticity, where efficacy is able to be achieved through consumption, while in contrast, authenticity is not able to be achieved through consumption. Zavestoski (2002) agrees that simplifiers use consumption to achieve their lower-end needs, however 
believes that such material consumption may have negative outcomes for the self, meaning they fail to achieve authenticity. Bekin et al. (2005) support this, finding that simplifiers are willing to accept lower levels of materialism believing less to be more; less choice but more quality.

Determining what 'makes' a voluntary simplifier with regard to their marketplace behaviour has proven to be problematic, and a reflection of the way the lifestyle has been defined or operationalised. For example, Iyer and Muncy (2009) define a voluntary simplifier as someone who purchases organic food, tries to buy goods made out of recycled materials and practices recycling. In an 18-item index developed by Leonard-Barton (1981), the most common activities undertaken by voluntary simplifiers are (in order): making gifts instead of buying, eating vegetarian main meals, changing their own car oil, receiving instructions on increasing self-reliance and recycling. However, Huneke (2005) finds that the most important activities undertaken by voluntary simplifiers are (in order): avoiding impulse purchases, recycling and eliminating clutter; with the two most common activities identified by Leonard-Barton (1981) being placed 16th and 20th, respectively. Given these differing results, and that little is understood about the lifestyle (McDonald et al., 2006), we suggest that qualitative methods may provide a more accurate understanding of the experiences of voluntary simplifiers, and the activities considered important by them.

The avoidance of clutter and reduced consumption are synonymous with voluntary simplicity, and the adoption of the lifestyle implies the disposition of material possessions (Nelson et al., 2007). In one of the earliest papers on disposition, Jacoby et al. (1977) argue that a consumer has three choices with regard to disposition behaviour: keeping an item (i.e. continuing to use it, converting it for another purpose, or storing it away for later use); permanently disposing of it (i.e. throwing an item away, giving it away, selling it, or trading it); or temporarily disposing of it (i.e. lending or renting an item to someone else).
Since Jacoby et al. (1977), research on disposition has focussed on possessions which are considered meaningful, such as the disposition of possessions of people who are living with or had died from AIDS (Kates, 2001), the disposition of meaningful possessions to strangers in garage sales and online auctions (Lastovicka and Fernandez, 2005), and the role of special possessions and their disposition by older consumers (Price et al., 2000). Disposition has also been looked at as a potential outcome of gift-giving behaviour (Sherry et al., 1992).

To date, the topic of disposition is one that has not been widely applied to the study of voluntary simplification. A notable exception to this is Bekin et al. (2007), who examined waste reduction strategies in environmentally friendly new consumption communites, finding that while recycling plays an important role, so does repairing and/or reusing possessions, as well as purchasing or selling products second-hand. With this, one can assume that the disposition behaviour of voluntary simplifiers includes possessions which can be considered mundane as opposed to meaningful, even though the latter has often been the focus of the disposition literature to date.

To help frame the contribution of this study, Figure 1 highlights several key themes from the voluntary simplicity and disposition literature. The main themes which emerge from the voluntary simplicity literature that are relevant to this study centre around the changes in consumption behaviour which occur as part of adopting the lifestyle, and can be viewed in terms of reducing consumption, ethical

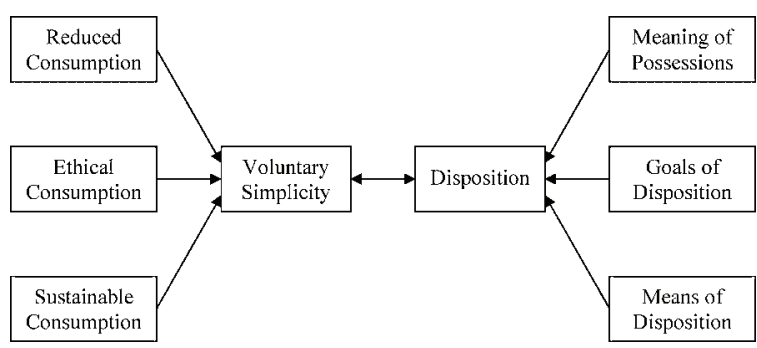

Figure 1. Key themes from the voluntary simplicity and disposition literature. 
consumption, and sustainable consumption. Reducing consumption involves limiting consumption through activities such as sharing, buying second-hand and eliminating clutter (e.g. Bekin et al., 2007; Craig-Lees and Hill, 2002; Huneke, 2005; Shaw and Newholm, 2002), while ethical consumption involves a person considering the environmental and social impacts of their consumption choices, which may result in activities like buying fairtrade and/or environmentally friendly products (e.g. McDonald et al., 2006; Shaw and Newholm, 2002). Voluntary simplifiers may also undertake sustainable consumption, where activities such as recycling and composting can occur (e.g. Bekin et al., 2007; Huneke, 2005). This focus on sustainable consumption may be as a result of ethical considerations (Shaw and Newholm, 2002), but may also be undertaken by a beginner voluntary simplifier who is not as concerned about ethical issues (McDonald et al., 2006).

The disposition literature also suggests three themes relevant to this study: the meaning of possessions, the goal of disposition activities and the means of disposition. The meaning of possessions focusses on issues such as the cherished or meaningful status which may be ascribed to an item (e.g. Kates, 2001; Price et al., 2000), as well as the public and private meanings of possessions (Lastovicka and Fernandez, 2005). The goals of disposition may include motives such as passing on a legacy through transferring ownership of an item to another person (Price et al., 2000), or as a means of consumer self-identification or identity construction (Lastovicka and Fernandez, 2005). Finally, the means of disposition includes many of the disposition choices identified by Jacoby et al. (1977) discussed earlier. Given these issues surrounding disposition, and the potential symbiotic roles of consumption and disposition in the voluntary simplicity lifestyle, this study aims to explore the disposition activities of voluntary simplifiers within the context of their overall consumption behaviour. To achieve this aim we adopt an interpretivist methodological approach (Lincoln and Guba, 1985), thus allowing us to understand the experiences of voluntary simplifiers in their own words.

\section{Metbod}

Twelve voluntary simplifiers from across the United States were interviewed for this study using a series of in-depth semi-structured interviews. Each interview was approximately 1 hour in length. Participants ranged in age from 21 to 72 , and were representative of the three levels of intensity identified by Etzioni (1998). Nine participants were female and three were male; consistent with the belief that females outnumber male voluntary simplifiers by a ratio of approximately ${ }^{\mathrm{Q} 2} 2: 1$ (Elgin, 1981). To recruit potential participants, both purposive and snowball sampling were used given the potential difficulty associated with identifying voluntary simplifiers, as they often have shared characteristics with involuntary simplifiers (Shama, 1981). Purposive sampling allowed participants to be selected on the basis of specific criteria (i.e. that they were living as a voluntary simplifier), and also allowed diversity to be built into the sample (Lincoln and Guba, 1985). Snowball sampling meant that those people interested in participating in this study could act as a link (Richie and Lewis, 2003), where they identified other potential participants. The details of the participants are provided in Table 1.

Table 1. Participant details

Name Age $\begin{aligned} & \text { Years of } \\ & \text { lifestyle }\end{aligned} \quad$ Adoption level

\begin{tabular}{llll}
\hline Jack & 29 & 10 years & Strong simplifier \\
Irene & 49 & 15 years & Strong simplifier \\
Belle & 49 & 25 years & Holistic simplifier \\
Ruby & 52 & 12 years & Holistic simplifier \\
Martha & 47 & 15 years & Holistic simplifier \\
Rick & 21 & 2 years & Downshifter \\
Sally & 36 & 9 years & Downshifter \\
Nicole & 64 & 40 years & Holistic simplifier \\
Leah & 42 & 5 years & Downshifter \\
Kirsty & 72 & 40 years & Holistic simplifier \\
Annie & 49 & 10 years & Holistic simplifier \\
Alf & 40 & 3 years & Downshifter \\
\hline
\end{tabular}

Copyright $\odot 2009$ John Wiley \& Sons, Ltd.
Journal of Consumer Behaviour, Month 2009

DOI: $10.1002 / \mathrm{cb}$ 
As an initial starting point to recruit participants, online communities which focussed on the topic of voluntary simplicity were used. These online communities were all part of the Yaboo! Groups network. Messages were posted in these communities outlining the research project, and invited people to contact the researchers via email for further information if they were interested in participating in the study. The interviews were all conducted online using Skype, a recently developed voice over-IP (VoIP) network (Skype, 2008). Pincott and Branthwaite (2000) discuss the benefits of online interviewing citing the ability for greater geographical reach at minimal cost, the speed and efficiency of contacting participants, and the greater anonymity afforded by the Internet encouraging candour and directness from participants. Such an approach is considered appropriate for this study given the large online presence of voluntary simplifier communities (Huneke, 2005).

The interviews had a phenomenological focus (i.e. they were from the perspective of the participants). This approach allowed participants to provide thick descriptions, where they were able to articulate their experiences as they perceived them. To analyse the consumption and disposition behaviour of participants, a within case analysis (Miles and Huberman, 1994) was used to gain insight, and was undertaken in the form of coding and sorting, which Tesch (1990) describes as decontextualising as the data are separated from their original cases. The data were then recontextualised through the identification of themes present across the cases (Tesch, 1990). These themes were the recurring concepts described by participants. Given the potential for multiple interpretations to arise from the data, two independent judges were used to authenticate the findings.

\section{Findings}

The interviews were conducted in order to explore the disposition activities of voluntary simplifiers within the context of their overall consumption behaviour. Participants discussed topics such as why they initially decided to adopt the lifestyle, the changes they had to make in order to do this, as well as their day-to-day experiences of living as a voluntary simplifier. From the interviews it was clear that disposition plays a dominant role in the early stages of adopting the lifestyle; and this forms the initial focus of our findings section. Subsequent to adopting the lifestyle, participants discussed their ongoing consumption behaviour, and the role disposition plays within this; and we report these findings later.

\section{Disposition activities of early voluntary simplifiers}

In the early stages of adopting the voluntary simplicity lifestyle, the disposition of material possessions is an implicit requirement (Nelson et al., 2007). Annie was representative of the participants interviewed in this study when she listed what she had done in order to adopt the lifestyle:

By moving to a less expensive house in a less expensive area paid off my mortgage, reduced my home energy usage, recycled or gave away many of my possessions, reduced the number of clothes I keep, reduced my car use to less than 2000 miles per year, started working from bome, bome educated my children, grow some of my own fruit, vegetables and herbs, cook most of our meals ourselves.

This highlights some of the initial disposition activities that occur when undertaking the lifestyle; her house was traded down and mortgage debt paid off, and many possessions were either given away to others or recycled. The other activities mentioned reveal reducedmaterial consumption and increased selfsufficiency, both of which are symptomatic of the voluntary simplicity lifestyle.

Voluntary simplifiers adopt the lifestyle for reasons such as concern for the natural environment, dissatisfaction with high-stress lifestyles and general anti-consumption atti- 
tudes (Huneke, 2005). The participants interviewed in this study shared many of these reasons, although some also alluded to a specific stage in life as being a key motivating factor, as Ruby suggested:

I think it finally comes to a point where enough is enough. Yes, that would be fair to say, and maybe part of it has to do with becoming my age. At middle age you finally discover who you are and what you really want or need, which is probably why there are so many divorces at this time in our lives as well. Another way to simplify, I might add, unloading relationships that no longer work. It's like you spend your 20's filling your space with stuff and around 40 or 50 you start unloading. I've found my friends are doing the same to some degree.

Thus, while supporting the idea that voluntary simplicity necessitates the disposition of material possessions, this quote suggests that wider changes may also occur; in this case, the re-evaluation of existing interpersonal relationships. Ruby also exemplifies how age may serve as an initial prompt for the disposition of possessions by older consumers (Price et al., 2000), and how disposition can be used as a means of identity construction (Lastovicka and Fernandez, 2005).

In the early stages of the lifestyle, many disposition activities were considered quite straight-forward, and were part of a general decluttering effort. The items that were initially disposed of were often disliked, and were the result of unplanned or impulse purchases, or an unwanted gift that had previously been received in a bad gift exchange (Sherry et al., 1992). As the following comment made by Sally suggests, duplicate items and items that had been held in storage were also considered easy to dispose of:

At first, I started getting rid of objects that I didn't like, like gifts from people, or family hand-me-downs. We slowly began to get rid of duplicate items we owned, like pots, pans, and coffee mugs. Also, items in storage that neither of us had touched in over a year.

Beyond these mundane items, participants were then confronted with possessions they considered meaningful; and which were either culturally bound or a reflection of self (Belk, 1988). Extending her previous thoughts, Sally explained:

Anything that didn't bold positive associations, I got rid of. That was easy but later, it became harder when I really had to take a good look at what we owned. It was like the stuff owned me instead of the other way around. I really started to question 'the American way' when our first and second sons were born. I looked around and we had so many toys and they didn't even seem interested in them all. I was a bit of a pack rat, so I felt like I was suffocating in stuff. Over time I came to learn fully that 'less is more'. For example, the children have longer attention spans when given less toys, and less choices.

Participants also spoke of meaningful possessions like books, other printed material and clothing. However, prior to their physical disposal, one participant (Nicole) stated how she would scan paper documents and save them electronically, even though she did not consider them part of her future as a voluntary simplifier. To her, disposition was focussed on removing the physical aspect of this particular possession, with the potential usefulness of it still being retained.

\section{The consumption bebaviour of voluntary simplifiers}

This section focusses on the consumption behaviour of voluntary simplifiers, and the role disposition plays within this. We first explore the consumption behaviour of participants in general terms, so we can understand the

Journal of Consumer Behaviour, Month 2009

DOI: $10.1002 / \mathrm{cb}$ 
context of their day-to-day behaviour. Then, we examine the themes which emerged from the interviews with regard to those factors they considered most important when making any consumption decision, and how disposition informs these decisions.

In terms of their retail consumption, participants were overwhelmingly utilitarian in the value they gained from shopping. All participants described the lack of pleasure gained from this activity, with many adding that shopping led to negative mood states. To address this, participants would try to reduce the number of times they needed to go shopping, shop locally, stockpile their purchases and combine their retail purchases into a single shopping trip. These descriptions emphasise the utilitarian values of task completion and shopping as a chore, similar to those articulated by Arnold and Reynolds (2003).

A common theme that emerged throughout the interviews was the general reduction in material consumption by participants. Rick summarised the feelings of all participants in this study when he stated 'I don't buy 'just to have' as much anymore'; a statement which supports Etzioni's (1998) definition of voluntary simplicity. When asked about their retail consumption behaviour, all participants initially spoke of food-often to supplement what they already grew themselves. Participants preferred to purchase food that was grown locally and organic; similarly preferring to purchase from farmers' markets rather than supermarkets. Basic food items were also preferred, with the emphasis on raw ingredients they could use to prepare their own meals. Participants often spoke of their physical health with regard to food, and argued that by visiting farmers' markets they could talk to the producer to guarantee the freshness and organic status of what they bought.

While food was a common purchasing experience shared by all participants, the interviews were primarily interested in understanding their wider consumption behaviour, and the role of disposition within this. Six themes emerged from the interviews, and these themes allow us to understand those factors participants considered most important when making any consumptionrelated decision. These themes, which will now be discussed in turn, are: environmental concerns, product quality, whether shared ownership is possible, whether an item is available second-hand or used, ethical products and self-sufficiency.

\section{Environmental concerns}

Participants were all similar in that they preferred goods to be environmentally friendly. However, participants were in either one of two groups; those who required goods to be environmentally friendly and those who preferred it, but it was not necessary for them to purchase an item. Those falling into the first group were fewer in number and spoke of their concern for others that live on earth, while those falling into the second group most often spoke of the inconvenience and cost associated with always purchasing environmentally friendly goods. For example, Leah commented:

If I'm saving a lot of time, or even a long trip to another store, then I might compromise and buy something less ecofriendly. When we bought our last washer-dryer, the only way we could have bought an official eco-friendly model would have been to expand the laundry closet in the condo where the unit resides.

When comparing the two groups, those in the first group were the type of simplifiers described by Etzioni (1998) as holistic; that is, they rearrange their entire life to fit the voluntary simplicity ethic. Those in the second group were most often downshifters, and to a lesser extent, the strong simplifiers of the participants interviewed, thus illustrating the different intensities the lifestyle can take. While environmental concerns were found to be an important consideration when 
making decisions about consumption, as the remainder of this section will show, these concerns were also prevalent when considering issues surrounding disposition. Specifically, the environmental costs of certain disposition activities (e.g. throwing an item away) were found to inform participants' consideration of what types of consumption would lessen future disposition. Nicole typified this approach, stating:

I am concerned about the inefficient use of natural resources and about the waste that is inberent in much of the manufactured consumer items in our society. I try not to use much packaging, supplying my own carrying bags when I go to a store and reusing things that can be reused.

\section{Product quality}

Many participants preferred to purchase items that they perceive to be good quality, with the assumption that they would be longer lasting. Martha typified many of the participants in this study when she observed:

I still look for quality, and have read Consumer Reports for big ticket items to reduce the risk of buying a lemon. I like to know that I won't have to replace or repair something for a long time.

This preference is consistent with the notion of voluntary simplicity, in that material consumption should be reduced. Participants argued that by buying quality goods that will be likely to last longer, they can reduce the number of times they have to purchase that particular item over the long term. In terms of monetary cost, participants were also willing to pay more for those goods they perceived to be of a higher quality. Overall, while quality products were associated with reduced consumption, participants also noted how this reduced consumption would mean disposition activities would be lessened; reflecting their environmental concerns about the disposal of worn out goods that can no longer be repaired. Jack summarised these concerns, stating:

I buy items made for quality, not cost. I make sure it's something that will last and not end up in the garbage in a year.

\section{Shared ownership}

Where possible, participants spoke of how they would prefer the benefits of shared (or community) ownership, so they did not need to purchase anything outright. Echoing Belk (2007), participants' desire for sharing often reflected their lessened focus on materialism. Libraries were mentioned when it came to items such as books, although participants talked about borrowing or hiring in order to reduce their own consumption in other areas. When it was not possible to borrow or hire an item, participants discussed how they would attempt to acquire what they wanted by buying second-hand. By sharing ownership, participants articulated how an item could be used for the required purpose, and then returned, thus avoiding unnecessary sole ownership and potential future disposition. Jack, like many participants, outlined the question he often asks himself about sharing:

Can I borrow it from someone or somewhere in order to reduce my own consumption? ... I borrow books or take them out from the library rather than buy new ... I also enjoy getting away on some weekends. This often involves renting or borrowing a car.

\section{Buying second-hand or used}

Participants preferred purchasing second-hand goods where possible, indicating that they were often eager beneficiaries of other consumers' disposition activities. The participants most commonly used thrift stores, craigslist.- 
com (an online classifieds listing service), and freecycle communities; supporting the idea that these communities are fertile grounds for voluntary simplifiers (Nelson et al., 2007). The act of buying second-hand, as opposed to new, was also considered a way of suppressing marketplace signals, as Nicole suggested:

When you buy an item new in a store, you send the manufacturer a signal that people want this item and more should be produced. When you buy second-hand, no signal is sent to anyone. Perfectly good items are recycled instead of landing in the landfill and you save money.

By purchasing second-hand goods, participants believed they were acting in an environmentally friendly manner; meaning less energy would be used by manufacturers, which helped lessen the effects of climate change. Participants were also found to contribute to the second-hand market by selling or giving away goods which they no longer required. As the following quote from Belle illustrates, by disposing of their unwanted goods, participants were able to support the communities in which they lived:

We buy outright the cars we still drive, thus avoiding the additional cost of interest, and keep the cars fairly well maintained until they are beyond sustainable. Then we donate them to goodwill organisations, where they are sold for funding of community or social programs.

\section{Ethical products}

Participants spoke of the requirement for a product to be ethical; although arguably, this was one of the least objective features used to appraise goods. This ethicality also had as much to do with the companies that produced the goods, if not more, than the goods themselves. The participants frequently mentioned the perceived injustices large compa- nies had committed, using this as a rationale to boycott their brands. In terms of the goods produced, participants considered issues such as whether recycled materials were used in their production, and the environmental effects of transporting the goods to market. Belle exemplified the concerns of many participants when she talked about the reasons why she preferred ethical products:

You must act in such a way that you truly respect nature and others on this planet, as well as the process which is used to produce all we consume ... destructive methods are so often used to produce what we use.

Many participants were also aware of the unethical manufacturing processes used by some companies, and used this awareness to inform the purchasing decisions they made on a day-to-day basis. In this regard, by purchasing ethical products, participants felt they were able to lessen the societal disposition costs of their consumption (e.g. if recycled materials have been used in the manufacturing process). Ethical reasons are an underlying factor why many people adopt the voluntary simplicity lifestyle (Shaw and Newholm, 2002), so it was not surprising that this consideration played an important role in many participants' consumption decisions.

\section{Self-sufficiency}

Participants showed high levels of self-sufficient behaviour, similar to the findings of Bekin et al. (2005). The participants also articulated a desire to become more self-sufficient in the future, with two simplifiers (Jack and Ruby) suggesting that they would like to live 'off the grid'. Other participants were less extreme, indicating they wanted to generate some of their own power through solar panels and grow more food, as they still relied on the marketplace for some of what they needed. Participants were not only self-sufficient in terms of food; many preferred to do their own repairs and where possible and make the 
things (e.g. clothes) they needed. Martha provided an example of this when talking about repairs on her house, stating:

We bave been able to fix our bouse, not consuming unnecessary things in the process. We repair things before replacing them.

By undertaking their own repairs, participants suggested they were able to prolong the life of their possessions, thus delaying or avoiding disposition, which they considered often has a negative effect on the environment. By carrying out their own repairs, participants were also able to exert some control over the quality of the work done.

\section{Discussion}

The aim of this paper was to explore the disposition activities of voluntary simplifiers in the context of their overall consumption behaviour. It was found that disposition does play an important role in voluntary simplifier behaviour, especially during the initial stages of the lifestyle. However, the disposition activities that occurred when first adopting the lifestyle differed markedly depending on the possessions involved. Many of the disposition activities described were quite straightforward, and could be considered part of a decluttering effort; although the items included here were often disliked, and were either unplanned or impulse purchases, or unwanted gifts. Possessions considered more meaningful and reflective of self were harder to dispose of; although overall, the participants reflected Nelson et al. (2007) in that they were eventually able to decouple their identity from these goods.

Six factors (themes) were found to guide the decision-making of participants when it came to their day-to-day consumption. These factors were environmental concerns, product quality, whether shared ownership is possible, whether an item is available second-hand or used, ethical products and self-sufficiency.
Although these factors informed participants' consumption decisions, their consideration of future disposition activities was also evident in each of these factors. From a consumption point-of-view, environmental concerns were prominent; however these concerns then permeated into their thoughts about the eventual disposition of goods, and what the environmental consequences of this disposition would be. For example, when discussing why they often bought higher quality products, participants argued that these products typically last longer and are more reliable. Even though they will still eventually break down beyond repair, they argued that it would at least take longer for this to occur than if they had bought a lesser quality product.

The participants also expressed a strong desire for shared ownership rather than individual possession for certain items. In this respect, they were avoiding the issue of disposition altogether; by not consuming (where possible) on an individual level, they also bypassed potential issues of disposition. Extending this, participants also preferred to buy second-hand or used goods where possible. They articulated that by doing so manufacturers would produce less, and that by purchasing second-hand they would reduce the number of unwanted items being thrown away. In this respect, participants reduced societal disposition (and the negative environmental costs associated with this) by being the recipients of other consumers' disposition activities. Participants were also found to dispose of their unwanted goods by participating in the second-hand market, or by donating or giving away possessions they no longer required. Echoing Shaw and Newholm (2002), ethical considerations were found to be important to participants when they considered their consumption activities.

Finally, where possible, the participants in this study tried to be as self-sufficient as possible. While food production was a common area of self-sufficiency, so too was the need to undertake their own repairs or to make the things they needed. By doing their own repairs, participants suggested that they were 
able to avoid or delay disposition. Overall, the findings of this study provide support to Bekin et al. (2007), in that recycling, repairing and/or reusing possessions, and purchasing or selling products second-hand were all activities undertaken by participants; however, this study also highlights several other areas where disposition informs the consumption decisions made by voluntary simplifiers.

\section{Limitations and future research}

The sample for this study consisted of voluntary simplifiers from the United States. Some previous voluntary simplification studies (e.g. Bekin et al., 2005; Craig-Lees and Hill, 2002) have included participants from other countries, so it would be worthwhile to explore whether any cultural differences exist with regard to the disposition behaviour of voluntary simplifiers. Another limitation stemming from the sample is that the simplifiers included in this study often fell on the 'extreme' side of the lifestyle; those described by Etzioni (1998) as holistic simplifiers. While the sample still included participants that could be considered downshifters, it would also be interesting to focus upon the disposition behaviour of non-voluntary simplifiers and beginner voluntary simplifiers (McDonald et al., 2006), and even more mainstream ethical or green consumers.

\section{Biographical notes}

Paul Ballantine is a Senior Lecturer in Marketing at the University of Canterbury in Christchurch, New Zealand. His research interests include retailing, consumption behaviour (particularly the negative aspects of consumption), and social and ethical issues in marketing.

Sam Creery is a Business Development Executive at Colgate-Palmolive New Zealand Ltd. He was formally a postgraduate student at the University of Canterbury in Christchurch, New Zealand, where his research interests were consumer behaviour and alternative consumption.

\section{References}

Arnold MJ, Reynolds KE. 2003. Hedonic shopping motivations. Journal of Retailing 79(2): 77-95.

Bekin C, Carrigan M, Szmigin I. 2005. Defying marketing sovereignty: voluntary simplicity at new consumption communities. Qualitative Market Research 8(4): 413-429.

Bekin C, Carrigan M, Szmigin I. 2007. Beyond recycling: 'commons-friendly' waste reduction at new consumption communities. Journal of Consumer Behaviour 6(5): 271-286.

Belk R. 1988. Possessions and the extended self. Journal of Consumer Research 15(2): 139-168.

Belk R. 2007. Why not share rather than own? Annals of the American Academy of Political and Social Science 611(1): 126-140.

Craig-Lees M, Hill C. 2002. Understanding voluntary simplifiers. Psychology \& Marketing 19(2): 187210.

Elgin D. 1981. Voluntary Simplicity: Toward a Way of Life That Is Outwardly Simple, Inwardly Rich. William Morrow: New York.

Etzioni A. 1998. Voluntary simplicity: characterization, select psychological implications, and societal consequences. Journal of Economic Psychology 19(5): 619-643.

Gregg R. 1936. The Value of Voluntary Simplicity. Pendle Hill: Wallingford, PA.

Huneke ME. 2005. The face of the un-consumer: an empirical examination of the practice of voluntary simplicity in the United States. Psychology \& Marketing 22(7): 527-550.

Iyer R, Muncy JA. 2009. Purpose and object of anticonsumption. Journal of Business Research 62(2): 160-168.

Jacoby J, Berning CK, Dietvorst TF. 1977. What about disposition? Journal of Marketing 41(2): 22-28.

Karp G. 2009. Simplify Your Life by Getting Rid of Clutter, Consuming Less. Available at http:// www.themorningcall.com/ [25 March 2009].

Kates SM. 2001. Disposition of possessions among families of people living with AIDS. Psychology $\varepsilon$ Marketing 18(4): 365-387.

Lastovicka JL, Fernandez KV. 2005. Three paths to disposition: the movement of meaningful posses- 
sions to strangers. Journal of Consumer Research 31(4): 813-823.

Leonard-Barton D. 1981. Voluntary simplicity lifestyles and energy conservation. Journal of Consumer Research 8(3): 243-252.

Lincoln YS, Guba EG. 1985. Naturalistic Inquiry. Sage: Beverly Hills, CA.

Maniates M. 2002. In search of consumptive resistance: the voluntary simplicity movement, In Confronting Consumption, Princen $\mathrm{T}$, Maniates M, Conca K (eds.) MIT Press: Cambridge, MA; 199-235.

McDonald S, Oates CJ, Young CW, Hwang K. 2006. Toward sustainable consumption: researching voluntary simplifiers. Psychology \& Marketing 23(6): 515-534.

Miles MB, Huberman AM. 1994. Qualitative Data Analysis: An Expanded Sourcebook. Sage Publications: Thousand Oaks.

Nelson MR, Rademacher MA, Paek H-J. 2007. Downshifting consumer $=$ upshifting citizen? An examination of a local freecycle community. Annals of the American Academy of Political and Social Science 611(1): 141-156.

Pincott G, Branthwaite A. 2000. Nothing new under the sun? International Journal of Market Research 42(2): 137-155.
Price LL, Arnould EJ, Curasi CF. 2000. Older consumers' disposition of special possessions. Journal of Consumer Research 27(2): 179-201.

Richie J, Lewis J. 2003. Qualitative Research Practice: A Guide for Social Science Students and Researchers. Sage Publications: London.

Shama A. 1981. Coping with stagflation: voluntary simplicity. Journal of Marketing 45(3): 120-134.

Shaw D, Newholm T. 2002. Voluntary simplicity and the ethics of consumption. Psychology $\&$ Marketing 19(2): 167-185.

Sherry JF, McGrath MA, Levy SJ. 1992. The disposition of the gift and many unhappy returns. Journal of Retailing 68(1): 40-65.

Skype. 2008. Available at http://www.skype.com/ [September 1 2008].

Taylor-Gooby P. 1998. Comments on Amitai Etzioni: voluntary simplicity: characterization, select psychological implications, and societal consequences. Journal of Economic Psychology 19(5): 645-650.

Tesch R. 1990. Qualitative Research: Analysis Types and Software Tools. Falmer Press: New York.

Zavestoski S. 2002. The social-psychological bases of anticonsumption attitudes. Psychology E Marketing 19(2): 149-165. 


\section{Author Query Form (CB/302)}

Special Instruction: Author please include responses to queries with your other corrections and return by e-mail.

Q1: Author: Please check the suitability of the suggested short title. Q2: Author: Please verify the change made in the sentence. 


\section{WILEY AUTHOR DISCOUNT CLUB}

We would like to show our appreciation to you, a highly valued contributor to Wiley's publications, by offering a unique $\mathbf{2 5 \%}$ discount off the published price of any of our books*.

All you need to do is apply for the Wiley Author Discount Card by completing the attached form and returning it to us at the following address:

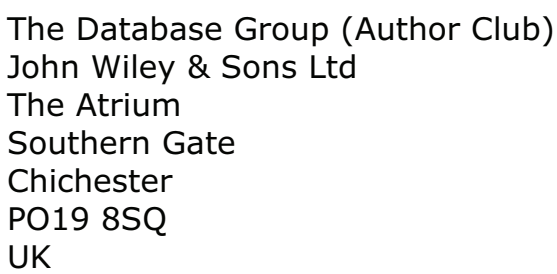

Alternatively, you can register online at www.wileyeurope.com/go/authordiscount Please pass on details of this offer to any co-authors or fellow contributors.

After registering you will receive your Wiley Author Discount Card with a special promotion code, which you will need to quote whenever you order books direct from us.

The quickest way to order your books from us is via our European website at:

\section{http: / / www.wileyeurope.com}

Key benefits to using the site and ordering online include:

- Real-time SECURE on-line ordering

- Easy catalogue browsing

- Dedicated Author resource centre

- Opportunity to sign up for subject-orientated e-mail alerts

Alternatively, you can order direct through Customer Services at:

cs-books@wiley.co.uk, or call +44 (0)1243 843294, fax +44 (0)1243 843303

So take advantage of this great offer and return your completed form today.

Yours sincerely,<smiles>CCCCC(C)CC(=O)OC</smiles>

Verity Leaver

Group Marketing Manager

author@wiley.co.uk

This offer is exclusive to Wiley Authors, Editors, Contributors and Editorial Board Members in acquiring books for their personal use. There must be no resale through any channel. The offer is subject to stock availability and cannot be applied retrospectively. This entitlement cannot be used in conjunction with any other special offer. Wiley reserves the right to amend the terms of the offer at any time. 


\section{REGISTRATION FORM For Wiley Author Club Discount Card}

To enjoy your $25 \%$ discount, tell us your areas of interest and you will receive relevant catalogues or leaflets from which to select your books. Please indicate your specific subject areas below.

Accounting

- Public

- Corporate

\section{Chemistry}

- Analytical

- Industrial/Safety

- Organic

- Inorganic

- Polymer

- Spectroscopy

Encyclopedia/Reference

- Business/Finance

- Life Sciences

- Medical Sciences

- Physical Sciences

- Technology

\section{Earth \& Environmental Science}

Hospitality

- Bioinformatics/ Computational Biology

- Proteomics

- Genomics

- Gene Mapping

- Clinical Genetics

[]
[]
[]

[ ] $]$

[ ]

[ ]

[]

[ ]

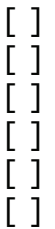

[]<smiles></smiles>

\section{Medical Science}

- Cardiovascular

- Diabetes

- Endocrinology

- Imaging

- Obstetrics/Gynaecology

- Oncology

- Pharmacology

- Psychiatry
Architecture

[ ]

Business/Management

Computer Science

- Database/Data Warehouse

[ ]

- Internet Business

- Networking

- Programming/Software Development

- Object Technology

[ ]

[

[]

Engineering

- Civil

[ ]

- Communications Technology

- Electronic

- Environmental

- Industrial

- Mechanical

[ ]

[ ]

[ ]

[]

[ ]

Finance/Investing

- Economics

- Institutional

- Personal Finance

Life Science

Landscape Architecture

Mathematics

Statistics

\section{Manufacturing}

Materials Science

Psychology

- Clinical

- Forensic

- Social \& Personality

- Health \& Sport

- Cognitive

- Organizational

- Developmental \& Special Ed

- Child Welfare

- Self-Help

Physics/Physical Science 
I confirm that I am (*delete where not applicable):

WILEY

a Wiley Book Author/Editor/Contributor* of the following book(s):

ISBN:

ISBN:

a Wiley Journal Editor/Contributor/Editorial Board Member* of the following journal(s):

Date:

\section{PLEASE COMPLETE THE FOLLOWING DETAILS IN BLOCK CAPITALS:}

TITLE: (e.g. Mr, Mrs, Dr) FULL NAME:

JOB TITLE (or Occupation):

DEPARTMENT:

COMPANY/INSTITUTION:

ADDRESS:

TOWN/CITY:

COUNTY/STATE:

COUNTRY:

POSTCODE/ZIP CODE:

DAYTIME TEL:

FAX:

E-MAIL:

\section{YOUR PERSONAL DATA}

We, John Wiley \& Sons Ltd, will use the information you have provided to fulfil your request. In addition, we would like to:

1. Use your information to keep you informed by post of titles and offers of interest to you and available from us or other Wiley Group companies worldwide, and may supply your details to members of the Wiley Group for this purpose.

[ ] Please tick the box if you do NOT wish to receive this information

2. Share your information with other carefully selected companies so that they may contact you by post with details of titles and offers that may be of interest to you.

[ ] Please tick the box if you do NOT wish to receive this information.

\section{E-MAIL ALERTING SERVICE}

We also offer an alerting service to our author base via e-mail, with regular special offers and competitions. If you DO wish to receive these, please opt in by ticking the box [ ].

If, at any time, you wish to stop receiving information, please contact the Database Group (databasegroup@wiley.co.uk) at John Wiley \& Sons Ltd, The Atrium, Southern Gate, Chichester, PO19 8SQ, UK.

TERMS \& CONDITIONS

This offer is exclusive to Wiley Authors, Editors, Contributors and Editorial Board Members in acquiring books for their personal use. There should be no resale through any channel. The offer is subject to stock availability and may not be applied retrospectively. This entitlement cannot be used in conjunction with any other special offer. Wiley reserves the right to vary the terms of the offer at any time. 